Part of Journal of Research of the National Bureau of Standards, Volume 28, February 1942

\title{
AN ABSOLUTE DETERMINATION OF THE AMPERE, USING HELICAL AND SPIRAL COILS
}

\author{
By Roger W. Curtis, Raymond L. Driscoll, and Charles L. Critchfield
}

\section{ABSTRACT}

The value of an electric current has been measured in absolute units by a current balance, and simultaneously in international units by standard cells and standard resistors. In the current balance a subdivided helix served as the two fixed coils and, as the moving coil, either a short helix or a compact spiral. The two moving coils were the same ones that were described in a previous paper in which the fixed coils were spirals.

The value obtained when using these two moving coils and the subdivided helix differs by only 4 parts in a million from the value obtained when using these moving coils and spirally wound fixed coils. These values are, however, somewhat different from those obtained when using multilayer coils wound with copper wire. The relationship between the absolute and International ampere, from the most dependable measurements at the National Bureau of Standards, may be expressed as

\section{NBS International ampere $=0.999850$ absolute ampere}

In the preceding paper published by members of the Bureau staff on this subject the value given was $1 \mathrm{NBS}$ International ampere $=0.999860$ absolute ampere.

\section{CONTENTS}

I. Introduction

II. Design and construction of the coils_._. 134

III. Measurements of the dimensions of the coils

1. Diameter

2. Pitch

3. Wire diameter.

IV. Electrical measurements

V. Computation of the force produced by unit current in the coils...- 144

1. The force between coaxial helices_._._.

2 . The force between a helix and a spiral

3 . Computation of the absolute value of the current

VI. Experimental determination of the maximum force between the coils........ 152

VII. Discussion of results_.

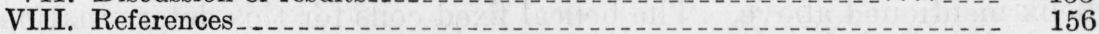

\section{INTRODUCTION}

The determination of a current in terms of the units of length, mass, and time is usually made by measuring the force between two or more coils carrying the current. The dimensions and positions of the coils can be measured, so that the current in the coils can be computed from their dimensions and the electromagnetic force between them. In most of the determinations made during this century, the coils have been of the multilayer type in which the cross-sectional 
dimensions of the windings were small compared with the diameter of the coils. The only important exception is the "current weigher" used at the National Physical Laboratory $[1],{ }^{1}$ which was constructed with single-layer helical coils. Previous determinations of the ampere at the National Bureau of Standards, using multilayer coils wound with wire [2,3], have shown that the effect of the uncertainty in the location of the wires in a multilayer coil is an important factor that cannot be evaluated. The problem has been attacked by building multilayer coils in the form of spiral ribbon windings, as already described [2]. Another approach to the problem has now been made by using single-layer helices exclusively or in combination with spiral ribbon coils, even though the smaller forces obtained reduced somewhat the accuracy of the force measurement. It is unlikely that all the systematic errors will be the same with the two types of fixed coils.

The technique [4] which has been developed at this Bureau for winding single-layer helices in lapped screw threads has produced coils which are well suited for use in a current balance. These coils have very small variations in diameter and in pitch. Two of these helices have been made for use in the current balance.

This report will be devoted to a description of the new coils used, the electric circuit, the formulas used in the computation of the current, and the results obtained. This report is reasonably complete in itself, but it will be necessary to refer to earlier papers for some of the details of the apparatus which have therein been described.

\section{DESIGN AND CONSTRUCTION OF THE COILS}

The coils for use in a current balance must fulfill the following requirements: (1) The electromagnetic force for the operating current must be sufficiently large to permit its accurate measurement; (2) the mass of the moving coil must be less than that for which the balance was designed; (3) the temperature of the coils when carrying the operating current must be not more than a few degrees above room temperature; (4) the dimensions of the coils must be such that they can be accurately measured; and (5) the distribution of the conductors in the coil must be sufficiently uniform to permit the accurate computation of the electromagnetic force. Spiral and helical coils meet the last condition more satisfactorily than the multilayer coils of wire which were used in an earlier determination [8]. Spiral fixed coils, a spiral moving coil, and a helical moving coil have already been described [2]. This paper gives the results of a determination in which helical fixed coils were used, the moving coils being the spiral and the belix mentioned above. The belical fixed coils for this determination were the two halves of a single helix. The two coils were obtained from one helix by connecting a lead to the midpoint of the winding and having the current flow in opposite directions in the two halves of the helix. The requirements given above will be discussed with reference to the use of the helical fixed coils.

The electromagnetic force between the helical fixed coils and the helical moving coil with an operating current of 1 ampere was about $1.4 \mathrm{~g}$ (grams) and with the spiral moving coil about $1.7 \mathrm{~g}$. While these forces were very small, they were sufficiently large to permit the

\footnotetext{
1 Figures in brackets indicate the literature references at the end of this paper.
} 
determination of a current within a few parts in a million for a single measurement. An increase in the current did not increase the accuracy because it produced additional heating in the coils.

The mass of the helical moving coil, designated as $P 1$, was $700 \mathrm{~g}$ and that of the spiral moving coil, designated as $A 1,475 \mathrm{~g}$. These coils were used on a balance which was designed to take a load of $2 \mathrm{~kg}$. Hence, both of these coils were well within the limits fixed by the balance.

The temperature of the coils was kept within a few degrees of room temperature by designing them to have low resistance, by using a small operating current, and by ventilating the coil case.

It was necessary that the coils be large enough so that their dimensions could be measured with the required accuracy. The moving coil had a diameter of about $25 \mathrm{~cm}$ and the fixed coil $45 \mathrm{~cm}$, and these dimensions met the above condition.

A satisfactory helical coil should have extremely uniform diameters and pitch of winding throughout the whole coil. Preliminary measurements were made with a fixed helix which had been used in an absolute determination of the ohm, where it was designated as the short glass solenoid [3]. However, theoretical considerations indicated that the pitch was not sufficiently uniform to give the required accuracy for the investigation on the ampere. Since a helix of the dimensions of this coil could be advantageously used in researches on the absolute ohm as well as on the absolute ampere, C. Moon rewound ${ }^{2}$ this form by the method which he had developed for producing helices of very uniform pitch and diameter [4]. Before winding, a helical groove or screw thread having a nominal pitch of $0.8 \mathrm{~mm}$ was ground in the cylindrical form. This groove was then lapped with a "saddle" or "half-nut" lap until the profile of the groove was approximately sinusoidal and the diameter of the form uniform. The helix was then wound with carefully selected wire drawn to size through several dies. The final drawing was made onto the grooved cylinder directly from the last drawing die, so that the winding tension of the wire was the tension with which the wire was pulled through the last die, which was about $10 \mathrm{~kg}$. After the winding was completed, elliptically shaped spots were polished on the wire along four lines parallel to the axis of the helix. Two lines were ruled on each spot on turns near the ends and middle of the winding. These ruled lines were used in measuring the pitch of the winding.

Three electric leads were attached to the fixed helix, now designated as $H 1$, one at each end and one at the midpoint. They projected radially through amber bushings in a wooden bar running parallel to the axis of the winding and about $2 \mathrm{~cm}$ outside of the coil winding. In order to attach the lead wires firmly and accurately, the end of each was notched, tinned, and held firmly against the winding at the desired location by a spring. By careful local heating, each lead wire was soldered onto the desired wire of the winding without disturbing the adjacent turns. This method of fastening the middle lead on the fixed helix made it unnecessary to break the winding at the middle. Hence this coil could be used in the absolute-ohm work as well as in the current balance.

2 Before rewinding the coil, Moon ground and lapped the screw thread, and, after the winding was completed, polished the "spots" on the wire and ruled the lines on them. 
The spiral coil, $A 1$, used as the second moving coil consisted of a double winding of aluminum ribbon on a form of aluminum alloy. The ribbon was anodized electroly tically to form an electrical insulating layer of aluminum oxide, which was the only insulation used between the successive turns of the coil. The resistance between the two windings $(50$ megohms) showed that no appreciable current was leaking between turns. The ratio of the radius of this coil to that of the helical moving coil had been indirectly determined by comparing them with several fixed coils as previously reported [2].

\section{MEASUREMENTS OF THE DIMENSIONS OF THE COILS}

The dimensions of the coils were measured by methods and with apparatus which had been used previously in similar measurements. It was necessary to measure the diameter and pitch of each helix, and each of these measurements had to be made with high precision. These will be described briefly and the results given in more detail.

\section{DIAMETER}

A ring micrometer, with a motor-driven screw and a tail stock having a pressure-operated contact, was set up for the measurement of the

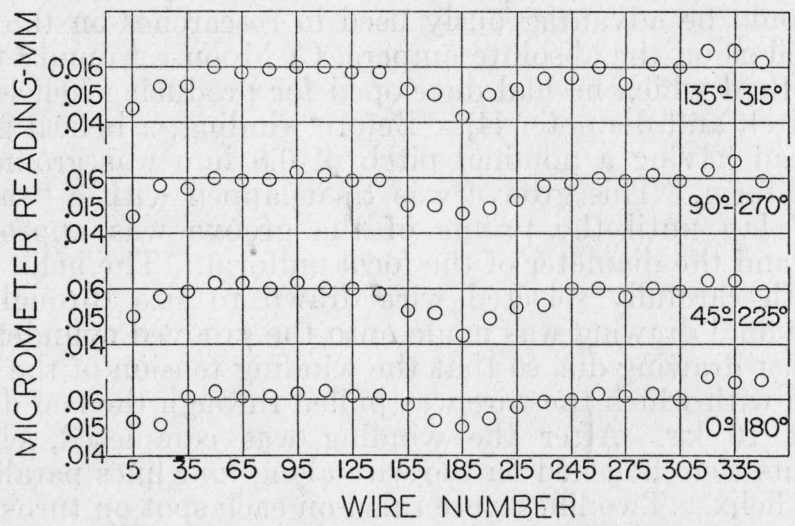

FIgURE 1.-Variation in the outside diameter of helical coil H1 along four axial planes.

diameters of the coils [5]. The coil to be measured was mounted on a turntable, with its axis vertical. The micrometer was hung in a horizontal position by three rods from a support which was carried on a vertical track. The coil could be rotated by the turntable to measure any diameter in a given horizontal plane, and the micrometer could be raised or lowered, by running the support up or down the vertical track, to measure any diameter along the length of the coil. The end standard to which the measurements were referred was mounted directly above the coil. The coil, micrometer, and end standard were mounted in a thermostatically controlled cabinet. The micrometer was adjusted and read from outside this cabinet. Readings could be estimated to 0.1 micron and repeated to 0.3 micron.

The diameter of the fixed coil, H1, was measured every $12 \mathrm{~mm}$ along the axis of the coil in each of four equally spaced axial planes. 
The measurements were made at two different temperatures for computing the temperature coefficient of expansion. The results are plotted in figure 1, and the average values at the different axial planes are given in table 1 . The value of $3.6 \mathrm{ppm} /{ }^{\circ} \mathrm{C}$ for the temperature coefficient agrees with the value given [6] for the type of Pyrex glass from which the form was made.

\section{TABLE 1.-Diameter and temperature coefficient of expansion of fixed coil H1}

[The value given for each axial plane is the average of 24 measurements along the length of the coil in that plane. The range in values in any axial plane did not exceed $0.00026 \mathrm{~cm}$. (See also fig. 1.) Length of fused-quartz end standard at $20^{\circ} \mathrm{C}: 46.31643 \mathrm{~cm}$. Assumed temperature coefficient of end standard: $0.4 \mathrm{ppm} /{ }^{\circ} \mathrm{C} .1$

[Date of measurements: August 1940.]

\begin{tabular}{|c|c|c|c|c|}
\hline & Axial plane & $\begin{array}{l}\text { Diameter } \\
\text { at } 26.0^{\circ} \mathrm{C}\end{array}$ & $\begin{array}{l}\text { Diameter } \\
\text { at } 30.9^{\circ} \mathrm{C}\end{array}$ & $\begin{array}{l}\text { Tempera- } \\
\text { ture co- } \\
\text { efficient }\end{array}$ \\
\hline $\begin{array}{l}0 \text { to } 180 \\
45 \text { to } 225 \\
90 \text { to } 270 \\
135 \text { to } 315\end{array}$ & Degrees & $\begin{array}{c}c m \\
46.26026 \\
46.26023 \\
46.26024 \\
46.26022\end{array}$ & $\begin{array}{c}c m \\
46.26108 \\
46.26108 \\
46.26103 \\
46.26099\end{array}$ & $\begin{array}{r}p p m /{ }^{\circ} C \\
3.6 \\
3.7 \\
3.5 \\
3.4\end{array}$ \\
\hline Aver & & 46.26024 & 46.26105 & 3.6 \\
\hline
\end{tabular}

Average outside diameter at $30.9^{\circ} \mathrm{C}$

Wire diameter (see table 5 )

Mean diameter of winding at $30.9^{\circ} \mathrm{C}$

Mean diameter of winding at $30.0^{\circ} \mathrm{C}$

The end standard, to which all the diameter measurements were referred, was made of fused quartz (clear silica glass). The ends of this standard were segments of a sphere which had its center at the midpoint of the standard. The length at $20^{\circ} \mathrm{C}$ was determined by the Interferometry Section of this Bureau. In obtaining the length of the end standard at different temperatures, the temperature coefficient of the fused quartz was assumed to be that given in the International Critical Tables, namely $0.4 \mathrm{ppm} /{ }^{\circ} \mathrm{C}$.

The diameters given in table 1 were measured without any current in the coil, so that the temperatures of the winding and of the form were the same. With a current in the coil, the temperature of the winding was higher than that of the form. The temperature of the winding under operating conditions was determined from its resistance, but no satisfactory method of measuring the temperature of the form has been developed. In order to obtain the effective temperature of the coil and winding, the diameter of $H 1$ was measured after it had carried a current of 1 ampere for several days and was under the same conditions as when in the current balance. Then the diameter was $1.8 \mathrm{ppm}$ smaller than that computed from the diameter and temperature coefficient given in table 1 and from the measured temperature of the winding. The appropriate correction was applied to the final result.

Two sets of measurements of the diameters of the moving coil, $P 1$, have been made. The measurements made in 1934 were to determine the variation in diameter. The correction for the measuring force was not applied, and the end standard was not accurately calibrated. In 1941 the diameter was measured at 3 different temperatures in 12 different axial planes in each of 11 different axial 
positions, from which the mean diameter and its temperature coefficient were determined. A summary of these measurements is given in table 2 .

\section{TABLE 2.-Summary of he measurements of the outside diameter of P1}

[The value given for each axial plane is the average of 11 measurements along the length of the coil in that plane. The average range in values in the different axial planes was $0.00031 \mathrm{~cm}$. Length of fused-quartz end standard at $20^{\circ} \mathrm{C}: 24.58618 \mathrm{~cm}$. Assumed temperature coefficient of end standard: $0.4 \mathrm{ppm} /{ }^{\circ} \mathrm{C}$. Measuring force: $450 \mathrm{~g}$. Date of measurements: February 1941]

\begin{tabular}{|c|c|c|c|}
\hline \multirow{2}{*}{ Axial plane } & \multicolumn{3}{|c|}{ Temperature of measurement } \\
\hline & $24.9^{\circ} \mathrm{C}$ & $30.0^{\circ} \mathrm{C}$ & $35.4^{\circ} \mathrm{C}$ \\
\hline $\begin{array}{l}\text { Degrees } \\
\text { 0 to } 180 \\
15 \text { to } 195 \\
30 \text { to } 210 \\
45 \text { to } 225 \\
60 \text { to } 240 \\
75 \text { to } 255 \\
90 \text { to } 270 \\
105 \text { to } 285 \\
120 \text { to } 300 \\
135 \text { to } 315 \\
165 \text { to } 330 \\
165\end{array}$ & $\begin{aligned} & c m \\
& 24.51303 \\
& .51325 \\
& .51338 \\
& .51334 \\
& .51315 \\
& .51272 \\
& .51227 \\
& .51207 \\
& .51207 \\
& .51220 \\
& .51250 \\
& .51274\end{aligned}$ & $\begin{array}{l}c m \\
24.51354 \\
.51375 \\
.51385 \\
.51388 \\
.51358 \\
.51322 \\
.51278 \\
.51256 \\
.51256 \\
.51268 \\
.51292 \\
.51327\end{array}$ & $\begin{array}{r}c m \\
24.51407 \\
.51425 \\
.51436 \\
.51439 \\
.51418 \\
.51372 \\
.51330 \\
.51310 \\
.51303 \\
.51321 \\
.51348 \\
.51379\end{array}$ \\
\hline Average $\ldots . . . . .$. & 24. 51273 & 24. 51322 & 24. 51374 \\
\hline
\end{tabular}

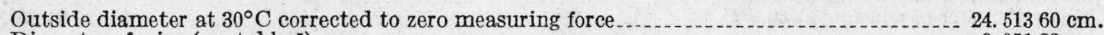
Diameter of wire (see table 5) _... Mean diameter of winding at $30.0^{\circ} \mathrm{C}$ Coefficient of thermal expansion in the range $25^{\circ}$ to $35^{\circ} \mathrm{C} \ldots \ldots \ldots$

Measurements of the diameter with a current in the winding gave the same value (within $1 \mathrm{ppm}$ ) as that computed from the measured diameter with no current and the measured temperature of the winding. This showed that the temperature of the winding and form were so nearly the same that no correction for their difference was necessary.

The mean diameter of the spiral moving coil, $A 1$, was obtained from the measured diameter of $P 1$ and the ratio of their radii. This ratio was obtained by comparison of the magnetic fields produced by known currents. Each of these coils was compared with six different fixed coils. The values of the ratio of radii at $22^{\circ} \mathrm{C}$ when each fixed coil was used as an intermediary were given in table 11 of the previous paper [2]. The diameter of $A 1$ was $25.15452 \mathrm{~cm}$ at $30^{\circ}$ 望C. The temperature coefficient was $21.0 \mathrm{ppm} /{ }^{\circ} \mathrm{C}$. With current in the coil, the temperature of the form was substantially the same as that of the winding.

The radial depth of $A 1$ and an approximate value of its mean diameter were obtained from mechanical measurements. The results depended on a measurement of the outside diameter, which did not give an accurate result because of the uncertainty in the correction for the measuring force. Also, the spacing of the individual ribbons in the radial direction may not have been exactly uniform because of the compression of the inner turns in the process of winding. This compression probably accounted for the fact that the mean diameter by mechanical measurements was $84 \mathrm{ppm}$ larger than that obtained by magnetic measurements. However, the uncertainty in the outside 
diameter and the compression of the windings were not sufficient to introduce a significant error in the value obtained for the radial depth, which was $0.6522 \mathrm{~cm}$ at $30^{\circ} \mathrm{C}$.

\section{PITCH}

The pitch of the helix, H1, was measured with a cathetometer $[7,4]$ equipped with two microscopes which could be alternately set on the coil and on a meter bar. The coil and the meter bar were mounted with their axes vertical, and the cathetometer was arranged so that it could be rotated about a vertical axis. Each microscope was focused on a ruled line on the wire opposite it. The cross hairs of the filar micrometer eyepiece of each microscope were set on the upper of the two lines in the field of view and the readings recorded. Readings were then taken for the lower lines on the same two spots. The cathetometer was rotated until the meter bar was brought into the field of view of the microscopes. Focusing was done by moving the meter bar with respect to the microscopes so that the original focusing position of the microscopes was not changed. The cross hairs of the filar micrometer eyepieces were then set on the millimeter rulings of the meter bar and the readings recorded. The number of turns between microscopes was chosen so that the distance measured was approximately a whole number of millimeters, and the meter bar was elevated so that the millimeter divisions were in the same part of the field of the eyepiece as the lines on the spots. From these readings and the calibrations of the meter bar and of the filar micrometer, the distance between the two wires was obtained.

Measurements were made on $H 1$ between five pairs of wires in each of three axial planes. A complete set was made at each of two different temperatures. From the measurement between each pair of wires, the pitch was obtained, and this was multiplied by the number of turns on the coil to give its length. Measurements made from the middle to each end showed that the pitch was only $6 \mathrm{ppm}$ different for the two halves. From the measurements at the two temperatures, the temperature coefficient of thermal expansion in the' axial direction was $3.0 \mathrm{ppm} /{ }^{\circ} \mathrm{C}$. The results of the measurements of the pitch of $H 1$ are given in table 3 . 


\section{Journal of Research of the National Bureau of Standards}

\section{TABLE 3.-Axial length and pitch of fixed coil H1}

[The recorded values are the distances between numbered turns. Length standard: calibrated invar meter bar BS3566. Temperature coefficient: $1.13 \mathrm{ppm} /{ }^{\circ} \mathrm{C}$. Date of measurements: July 1940]

\begin{tabular}{|c|c|c|c|c|c|c|}
\hline \multirow{3}{*}{ Axial interval } & \multicolumn{6}{|c|}{ Axial planes } \\
\hline & \multicolumn{2}{|c|}{$0^{\circ}$} & \multicolumn{2}{|c|}{$180^{\circ}$} & \multicolumn{2}{|c|}{$270^{\circ}$} \\
\hline & $31.5^{\circ} \mathrm{C}$ & $26.4^{\circ} \mathrm{C}$ & $31.5^{\circ} \mathrm{C}$ & $27.0^{\circ} \mathrm{C}$ & $31.4^{\circ} \mathrm{C}$ & $27.0^{\circ} \mathrm{C}$ \\
\hline $\begin{array}{l}\text { Turns } \\
350 \text { to } 5 \\
349 \text { to } 4 \\
348 \text { to } 3 \\
347 \text { to } 2 \\
346 \text { to } 1\end{array}$ & $\begin{array}{r}c m \\
27.59682 \\
.59644 \\
.59660 \\
.59677 \\
.59667\end{array}$ & $\begin{array}{r}c m \\
27.59634 \\
.59604 \\
.59618 \\
.59628 \\
.59618\end{array}$ & $\begin{array}{r}c m \\
27.59660 \\
.59667 \\
.59660 \\
.59664 \\
\end{array}$ & $\begin{array}{r}c m \\
27.59613 \\
.59630 \\
.59630 \\
.59638 \\
.59616\end{array}$ & $\begin{array}{r}c m \\
27.59652 \\
.59667 \\
.59660 \\
.59670 \\
.59667\end{array}$ & $\begin{array}{r}c m \\
27.59618 \\
.59633 \\
.59633 \\
.59646 \\
.59633\end{array}$ \\
\hline A verage & 27.59666 & 27.59620 & 27.59663 & 27.59625 & 27.59663 & 27.59633 \\
\hline $\begin{array}{l}\text { Coefficient of thermal expan- } \\
\text { sion }\end{array}$ & \multicolumn{2}{|c|}{$3.3 \mathrm{ppm} /{ }^{\circ} \mathrm{C}$} & \multicolumn{2}{|c|}{$3.1 \mathrm{ppm} /{ }^{\circ} \mathrm{C}$} & \multicolumn{2}{|c|}{$2.7 \mathrm{ppm} /{ }^{\circ} \mathrm{C}$} \\
\hline
\end{tabular}

Mean axial length of 345 turns. $27.59664 \mathrm{~cm}$ at $31.5^{\circ} \mathrm{C}$ Mean pitch axial length of 172 turns.

Mean coefficient of thermal expansion.

a Measurements made at the $90^{\circ}$ position were not satisfactory. This set of spots was ruled first, and because of difficulties encountered in setting up the ruling device when the spacing between the wires was so small, the lines were not evenly placed with respect to the edges of the wires. Therefore, the few measurements made at this position are not reported.

Note-The half-lengths were measured at the $0^{\circ}$ and $180^{\circ}$ positions. The pitch of the wires 181 to 1 was $6 \mathrm{ppm}$ greater than that for wires 350 to 175. The length of each half of the helix was taken as the average pitch for the whole helix multiplied by 172 , the number of turns in each half.

The pitch of the helical moving coil, $P 1$, though relatively unimportant, was measured in somewhat the same way as for $H 1$, except that the axis of the coil was mounted in a horizontal position and a single microscope used. This microscope was mounted on a track and its position determined by an accurate micrometer screw. Before and after each set of measurements the screw was calibrated in place by settings made on a line standard. Measurements were made of the length of the whole coil and also of each half. The temperature coefficient was not measured, since the coil was so short that the change in length with any change in temperature encountered in these measurements was negligible. The results of these measurements are given in table 4.

TABLE 4.-Axial length and pitch of moving coil $\mathrm{P} 1$ at $24^{\circ} \mathrm{C}$

[Length standard: stainless steel decimeter bar BS 6. Temperature coefficient: $10.3 \mathrm{ppm} /{ }^{\circ} \mathrm{C}$. Date of measurements: October 1934]

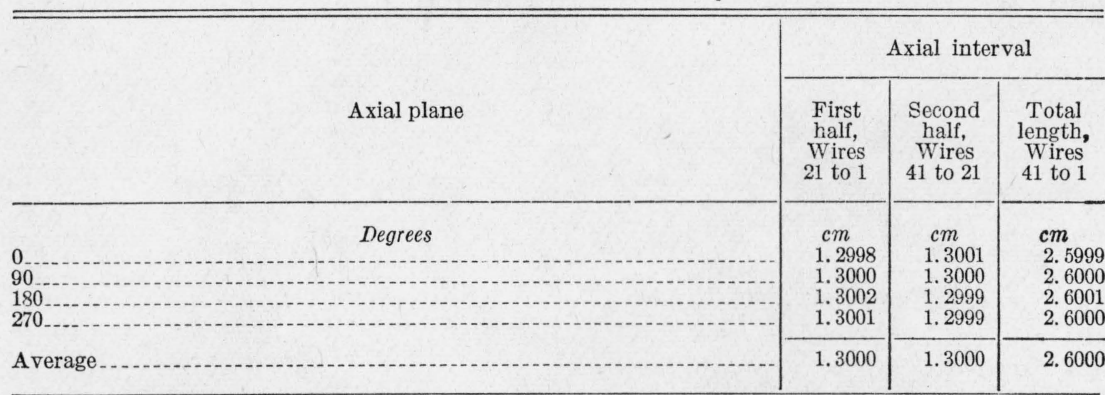

Average length of 40 turns. 
The measurement of pitch for the spiral moving coil, $A 1$, has no meaning in the usual sense because there is only one turn in the axial direction, although there are many layers. The corresponding measurement is the axial breadth of the winding, and in this case it is the width of the ribbon itself. This was measured with an ordinary micrometer and a clamp for holding the ribbon flat. Samples of the ribbon, taken before and after winding, were measured. The average width of the ribbon was found to be $0.6364 \mathrm{~cm}$, without insulation and this figure may be taken as the axial breadth of the winding, since, within reasonable limits, the uneven stacking of the winding in an axial direction has been shown to have a negligible effect [2].

\section{WIRE DIAMETER}

The diameter of the wire was measured with a special micrometer set up for that purpose [4]. The head and tail stock were of the same type as those used in measuring the diameters of the coils, except that the screw was hand-operated and a small light was used to indicate when the contact on the tail-stock was opened. The wire to be measured hung from a support above the micrometer and was kept straight by means of a weight of about $5 \mathrm{~kg}$. The wire was stretched on the form by a force of about $10 \mathrm{~kg}$. A correction to the measured diameter on account of the difference in tension was made using a value of 0.34 for Poisson's ratio. The support could be rotated so that any diameter in a given cross section could be measured, and the micrometer could be raised or lowered to measure at any particular place along the length of the sample. Readings could be made to 0.1 micron and could be repeated to 0.2 micron.

The diameter of the wire of each helix was obtained from samples taken from the beginning and end of the winding. The diameter of each sample was measured in either four or eight different angular positions around the wire. Each sample from $H 1$ was measured at several places along the wire. In addition, an average value of the diameter of a sample of the wire of $H 1$ was obtained by measuring its mass, length, and density. A correction was made for the decrease in density of the wire when it was under tension on the coil. Estimates of the accuracy obtained in the measurement of the three quantities used in this method indicated that the precision of the mechanical and density methods was about the same. The results are summarized in table 5 .

The wire for $H 1$ was drawn through a diamond die having a nominal diameter of $0.7 \mathrm{~mm}$. The measurements showed that the wire was slightly elliptical. The wire for the small moving coil, P1, was drawn through a sapphire die having a nominal diameter of $0.51 \mathrm{~mm}$. A set of measurements on this wire showed it to be somewhat less elliptical than the wire on $H 1$.

The average value of the diameter of the wire was taken as the mean of the values obtained by the mechanical and density methods for $H 1$ and as the mean of the mechanical measurements for $P 1$. However, the important diameter was the one which was perpendicular to the axis of the coil, since it was the one which was subtracted from the outside diameter of the coil winding to get the mean diameter. A small correction to the average value, which was negative in the 
case of $H 1$ and zero in the case of $P 1$, was obtained from the data for the variation of the wire diameter with angular position.

The values of the various constants of the coils are assembled in table 6.

\section{TABLE 5.-Diameter of the wire used on $H 1$ and P1}

[Temperature: between $28^{\circ}$ and $29^{\circ} \mathrm{C}$. Date of measurements: July 1937 for $P 1$ and July 1940 for H1]

Average by mechanical measurements

Difference between maximum and minimum diameters.

A verage by mechanical measurements

Average by density, length, and mass measurements

Final average.

Difference between the diameter perpendicular to the axis of the coil and the average wire diameter.

Final average wire diameter perpendicular to the axis of the coil.

\begin{tabular}{|c|c|c|c|}
\hline \multicolumn{2}{|c|}{$H 1$} & \multicolumn{2}{|c|}{$P 1$} \\
\hline End $A$ & End $B$ & End $A$ & End $B$ \\
\hline $\begin{array}{c}m m \\
0.6994 \\
.0012\end{array}$ & $\begin{array}{r}m m \\
0.7000 \\
.0022\end{array}$ & $\begin{array}{l}m m \\
0.5124 \\
.0008\end{array}$ & $\begin{array}{r}m m \\
0.5123 \\
.0009\end{array}$ \\
\hline \multicolumn{2}{|c|}{$\begin{array}{r}0.6997 \\
.7005 \\
.7001\end{array}$} & \multicolumn{2}{|c|}{0.5123} \\
\hline-0.0005 & -0.0005 & 0.0000 & 0.0000 \\
\hline \multicolumn{2}{|c|}{0.6996} & \multicolumn{2}{|c|}{0.5123} \\
\hline
\end{tabular}

TABLe 6.-Constants of the fixed helix $H 1$ and the moving coils P1 and A1

[All values reduced to $30^{\circ} \mathrm{C}$.]

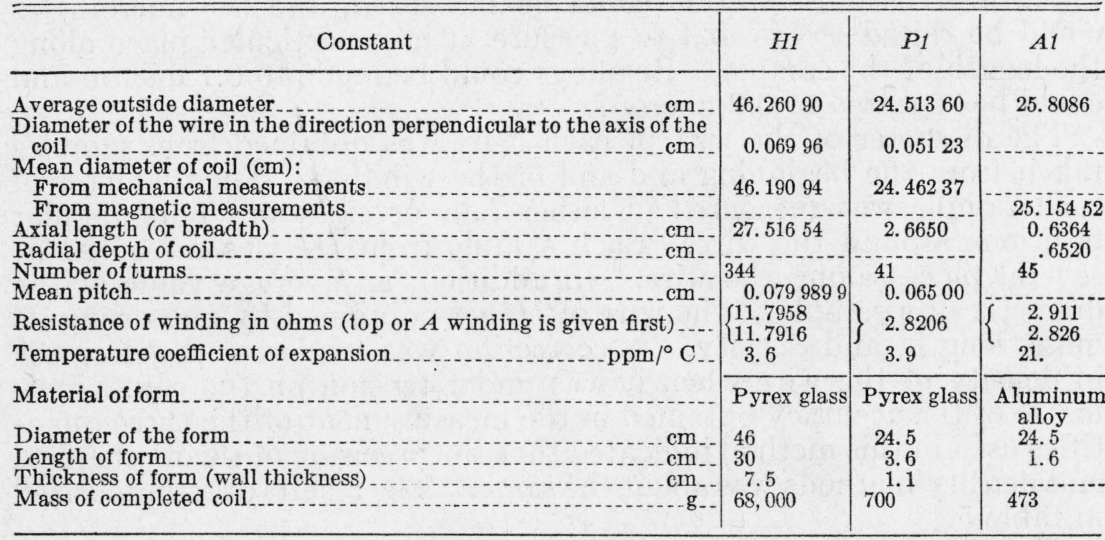

\section{ELECTRICAL MEASUREMENTS}

The measurement of the current through the windings of the coils in NBS International amperes was made by comparing the potential drop across a calibrated resistor with the electromotive force of a standard cell, and computing the current from Ohm's law. A simple circuit was arranged which reduced to a minimum possible troubles from thermal electromotive forces, electric leakage, and calibration errors. A diagram of the circuit is given in figure 2 .

The current from the battery, $B$, divided at the midpoint of the fixed helix, $H 1$, so that the values of the currents in the two halves had to be determined separately in NBS International amperes. One current was measured directly and the other obtained from the ratio of the two. The current was measured directly by balancing 
the potential drop it produced in the calibrated resistor, $R 1$, against the electromotive force of the standard cell, $E$. The ratio of currents was measured by a type of bridge circuit in which the calibrated resistor, $R 1$, was connected in series with the moving coil and onehalf of the fixed coil, and another calibrated resistor, $R 2$, was connected in series with an adjustable resistor, $R 3$, and the other half of the fixed coil. A storage battery, $B$, was connected in series with an adjustable ballast resistor, $R 4$, and a reversing switch, $S 1$. The two parallel portions of the circuit extended from the midpoint of the fixed coil to the contact which connects the calibrated resistors, $R 1$ and $R 2$, on the slide wire, $S W$. A galvanometer, $G 1$, was arranged

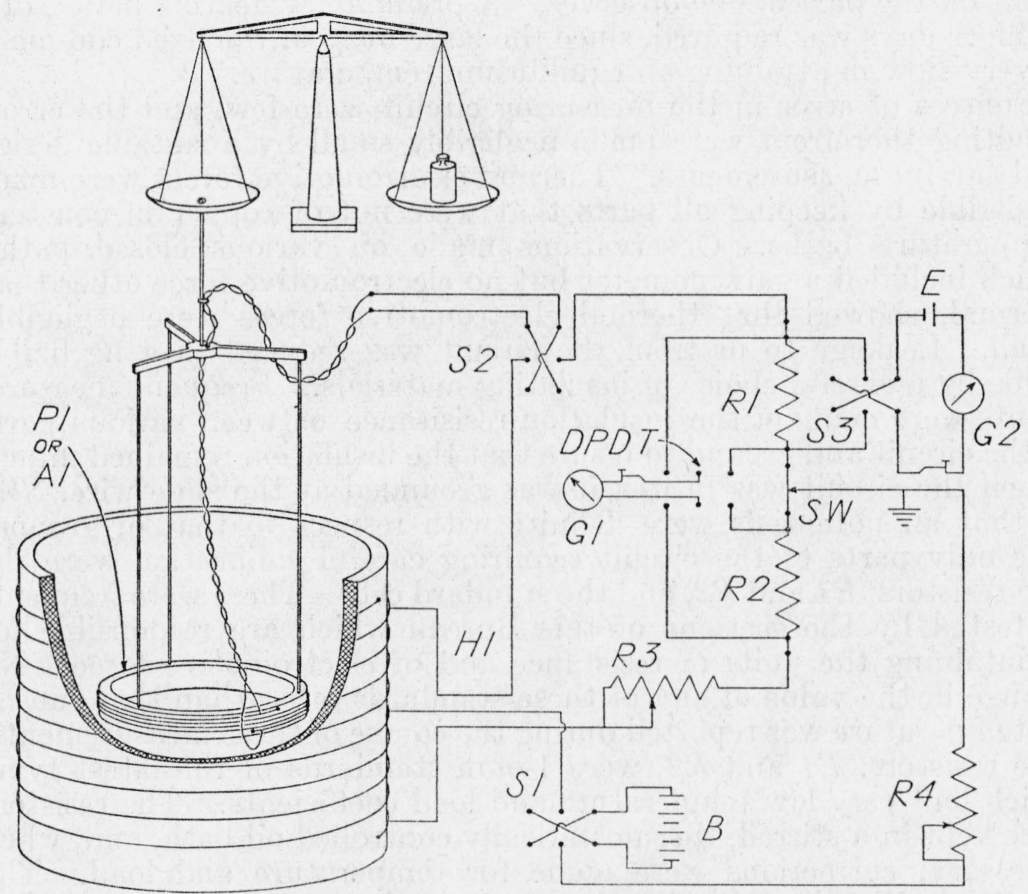

FIgURE 2.-Diagram of the electric circuit of the current balance when using H1 for the two fixed coils.

so that it could be connected to either set of the potential terminals of the calibrated resistors through the switch, $D P D T$. By adjusting resistor $R S$ and the slide wire, $S W$, the galvanometer deflection could be made zero for both sets of potential terminals. Then the ratio of the currents was equal to the inverse ratio of the resistance of resistors $R 1$ and R2. The current in the upper half of the fixed coil was measured by connecting a standard cell, $E$, and a galvanometer, GR, across resistor $R 1$ and adjusting the ballast resistor, $R 4$, until the galvanometer had a zero deflection. This adjustment did not affect the ratio of the currents in the two halves of the coil. When both galvanometers gave no deflection, the current in one-half of the fixed coil and the moving coil was known in NBS International amperes from the resistance of the calibrated resistor $R 1$ and the electromotive force, $E$, of 
the standard cell, and the ratio of the currents was known from the inverse ratio of the calibrated resistors $R 1$ and $R 2$. In practice $R 1$ and $R 2$ were very nearly equal, so that the two currents had nearly the same value.

It was more convenient in the computation of the final result to use a mean current rather than the two individual values. This mean current was called the equivalent current and was the square root of the product of the current in the moving coil and the average current in the two halves of the fixed coil.

With a large-capacity storage battery the currents could be kept steady to within 1 or 2 parts in a million by almost continuous adjustment on the part of one observer. A preliminary heating period of 2 or more days was required, since the large mass of the fixed coil made it very slow in attaining an equilibrium temperature.

Sources of error in the measuring circuit were few, and the errors resulting therefrom were made negligibly small by a suitable design and careful measurements. Thermal electromotive forces were made negligible by keeping all parts that were not of copper in constant temperature baths. Observations made on various closed paths, which included a galvanometer but no electromotive force other than thermal, showed that thermal electromotive forces were negligibly small. Leakage to or from the circuit was reduced to a negligible value by a careful choice of insulating materials. Frequent measurements were made of the insulation resisitance between various parts of the circuit and ground to insure that the insulation remained intact. When the circuit was in use, it was grounded at the slide wire, $S W$, so that all potentials were definite with respect to that of ground. The only parts of the circuit requiring careful calibration were the two resistors, $R 1$ and $R 2$, and the standard cell. These were frequently tested by the sections of this Bureau which are responsible for maintaining the units of resistance and of electromotive force. No change in the value of any of these standards other than that caused by temperature was reported during the course of these measurements. The resistors, $R 1$ and $R 2$, were 1-ohm standards of the latest type, which had very low temperature and load coefficients. The resistors were kept in a stirred, thermostatically controlled oil bath, and, when necessary, corrections were made for temperature and load. The standard cells were kept in an underground compartment, where the temperature changed very slowly, so that frequent comparisons with the standards of this Bureau enabled their electromotive force to be determined at any time from the observed temperature. This combination of standard cells and standard resistors gave a current of about 1.018 amperes.

\section{COMPUTATION OF THE FORCE PRODUCED BY UNIT CURRENT IN THE COILS}

The computation of the force produced by a unit current in both the fixed and the moving coils requires a different formula when the moving coil and the fixed coil are both helices than that required when a helix is used with a spiral coil. The two cases will be considered separately. Because the formulas take quite different forms, the nomenclatures for the two cases are distinct. 


\section{THE FORCE BETWEEN COAXIAL HELICES}

A formula for the force between two coaxial helical wires when each carries unit current has been given by Snow [10]. This formula is perfectly general so far as the relative vertical positions of the two coils are concerned. The permeability at all points is assumed to be unity. The coils of the current balance were arranged as shown in figure 3 in order to obtain the maximum vertical force on the suspended coil, $P 1$. In all that follows, Snow's formula has been applied in accordance with the arrangement of the coils as shown.

The following independent variables are used in the formula

$r_{1}=$ mean radius of the fixed helix.

$r_{2}=$ mean radius of the moving helix.

$l_{1}=$ axial length of the fixed helix (pitch $\times$ number of turns).

$l_{2}=$ axial length of the moving helix (pitch $\times$ number of turns).

$N_{1}=$ number of turns on fixed coil.

$\mathrm{N}_{2}=$ number of turns on moving coil.

$\alpha=$ angular separation of the leads on the two helices.

The axial force, $f$, between the suspended coil, $P 1$, and the upper half of the solenoid, H1, produced by unit current in each coil, is computed from the same function of three different quantities, $X_{1}$, $X_{2}$, and $X_{3}$, by the equation

$$
f=2 \omega^{\prime}\left(X_{1}\right)+\omega^{\prime}\left(X_{2}\right)-\omega^{\prime}\left(X_{3}\right) .
$$

The three quantities, $X_{1}, X_{2}, X_{3}$, are derived from the lengths of the coils as follows:

$$
\begin{aligned}
& X_{1}=\frac{l_{2}}{2} \\
& X_{2}=\frac{l_{1}-l_{2}}{2} \\
& X_{3}=\frac{l_{1}+l_{2}}{2} .
\end{aligned}
$$

The function $\omega^{\prime}(X)$ is resolved into three components; $\omega^{\prime}{ }_{\theta}(X)$, the principal term; $\omega^{\prime}{ }_{a}(X, \alpha)$, a correction term depending upon the relative azimuths of the two helices; and $\bar{\omega}^{\prime} X(X, \alpha)$, a correction term for the axial component of current in the helices and lead wires. These terms are given by the equations:

$$
\begin{aligned}
\omega_{\theta}^{\prime}(X)= & \frac{2 \pi N_{1} N_{2}}{l_{1} l_{2}}\left\{X \sqrt{X^{2}+\left(r_{1}+r_{2}\right)^{2}}[K-E]+\frac{X\left(r_{1}-r_{2}\right)^{2}}{\sqrt{X^{2}+\left(r_{1}+r_{2}\right)^{2}}}[K-\Pi]\right\} \\
\omega^{\prime}{ }_{a}(X, \alpha)= & \frac{\pi X}{6 \sqrt{X^{2}+\left(r_{1}+r_{2}\right)^{2}}}\left[\frac{2-k^{2}}{1-k^{2}} E-2 K\right] \\
+ & \frac{\pi X}{4 \sqrt{r_{1} r_{2}}}\left\{\cos \frac{\alpha}{2} \sin ^{-1}\left(k \cos \frac{\alpha}{2}\right)-\frac{k\left(2-k^{2}\right)}{2\left(1-k^{2}\right)} \sqrt{1-k^{2} \cos ^{2} \frac{\alpha}{2}}\right. \\
& \left.+\sin \frac{\alpha}{2} \log _{e}\left[\frac{k \sin \frac{\alpha}{2}+\sqrt{1-k^{2} \cos ^{2} \frac{\alpha}{2}}}{\sqrt{1-k^{2}}}\right]\right)
\end{aligned}
$$

$\widetilde{\omega}_{X}^{\prime}(X, \alpha)=\frac{X}{\sqrt{X^{2}+\left(r_{1}+r_{2}\right)^{2}}} \log _{e} \frac{r_{1}}{\sqrt{r_{1}^{2}+r_{2}^{2}-2 r_{1} r_{2} \cos \alpha}}$,

where $k^{2}=4 r_{1} r_{2} /\left[X^{2}+\left(r_{1}+r_{2}\right)^{2}\right]$

$k_{0}^{2}=4 r_{1} r_{2} /\left(r_{1}-r_{2}\right)^{2}$ 
and $K, E, \Pi$ are the complete elliptic integrals of the first, second, and third kinds, respectively, to the modulus $k$ and parameter $k_{0}$. These integrals can be evaluated conveniently by the AGM method as outlined by King [11] and by Grover [12]. Because the value of $f$ is the difference of quantities that are nearly equal, the computation of the $\omega^{\prime}$ functions must be carried to more significant figures than are required in the result.

As shown in figure 3, the fixed coil, $H 1$, was divided into two parts that were practically identical; equal and opposite currents in the

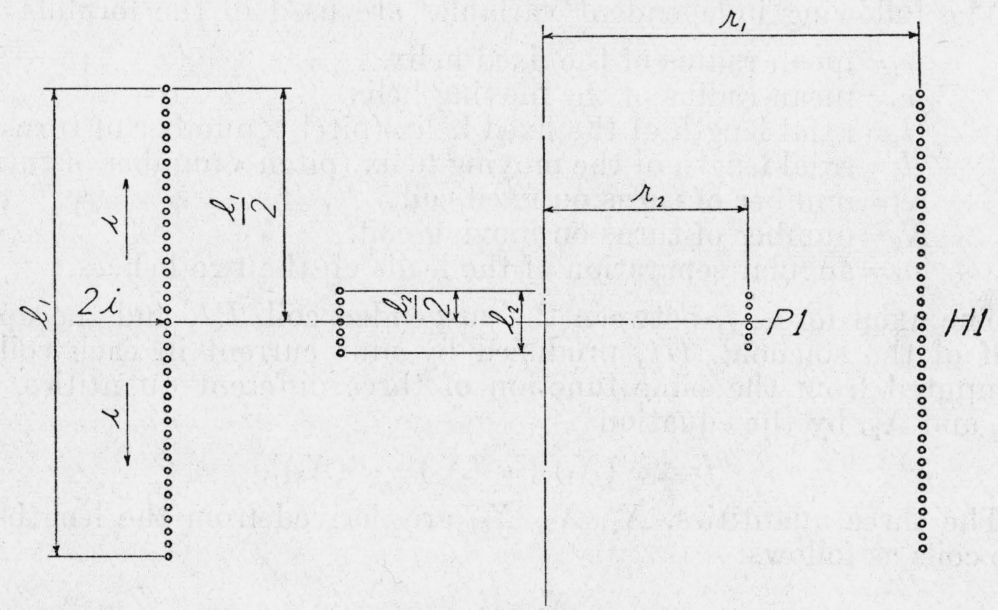

Figure 3.-Section showing relative positions of helices P1 and H1.

two halves of $H 1$ doubled the force, $f$, which, as stated before, was the attraction of unit current in the moving coil, $P 1$, for unit current in the upper half of $H 1$ only. Furthermore, the force measured by the balance was that caused by reversing the current in the fixed coils. This procedure doubled the force that would have been obtained if the observations had been made with the current "off" and "on." The value of $f$ is in dynes if the permeability of the medium surrounding the coils is unity. Hence, the total force, $F_{H H}$, in dynes for an absolute ampere in each coil is

$$
F_{H H}=4 f / 100 \text {. }
$$

Since the correction terms $\omega^{\prime}{ }_{a}(X, \alpha)$ and $\bar{\omega}_{X}^{\prime}(X, \alpha)$ are small, adjustments in the value of the force for unit currents corresponding to small 
corrections to the nominal values of $r_{1}, r_{2}, l_{1}$, and $l_{2}$ can be made by means of the following variation formula:

$$
\begin{aligned}
& \frac{\delta f}{f}=\frac{\delta F}{F}=\left\{\frac{\left[\frac{2 d \omega^{\prime}{ }_{\theta}\left(X_{1}\right)}{d r_{1}}+\frac{d \omega^{\prime}{ }_{\theta}\left(X_{2}\right)}{d r_{1}}-\frac{d \omega^{\prime}{ }_{\theta}\left(X_{3}\right)}{d r_{1}}\right]}{2 \omega^{\prime}{ }_{\theta}\left(X_{1}\right)+\omega^{\prime}{ }_{\theta}\left(X_{2}\right)-\omega^{\prime}{ }_{\theta}\left(X_{3}\right)}\right\} \frac{\delta r_{1}}{r_{1}} \\
& +\left\{\left[\frac{\left[\frac{2 d \omega^{\prime}{ }_{\theta}\left(X_{1}\right)}{d r_{2}}+\frac{d \omega^{\prime}{ }_{\theta}\left(X_{2}\right)}{d r_{2}}-\frac{d \omega_{\theta}{ }_{\theta}\left(X_{3}\right)}{d r_{2}}\right]}{2 \omega^{\prime}{ }_{\theta}\left(X_{1}\right)+\omega^{\prime}{ }_{\theta}\left(X_{2}\right)-\omega^{\prime}{ }_{\theta}\left(X_{3}\right)}\right\} \frac{\delta r_{2}}{r_{2}}\right. \\
& +\left\{\left[\frac{\left[\frac{2 d \omega_{\theta}^{\prime}\left(X_{1}\right)}{d l_{1}}+\frac{d \omega^{\prime}{ }_{\theta}\left(X_{2}\right)}{d l_{1}}-\frac{d \omega_{\theta}{ }_{\theta}\left(X_{3}\right)}{d l_{1}}\right]}{2 \omega^{\prime}{ }_{\theta}\left(X_{1}\right)+\omega^{\prime}{ }_{\theta}\left(X_{2}\right)-\omega^{\prime}{ }_{\theta}\left(X_{3}\right)}\right] l_{1}\right\} \frac{\delta l_{1}}{l_{1}} \\
& +\left\{\left[\frac{\left.\frac{2 d \omega_{\theta}^{\prime}\left(X_{1}\right)}{d l_{2}}+\frac{d \omega^{\prime}{ }_{\theta}\left(X_{2}\right)}{d l_{2}}-\frac{d \omega_{\theta}^{\prime}\left(X_{3}\right)}{d l_{2}}\right]}{2 \omega^{\prime}{ }_{\theta}\left(X_{1}\right)+\omega^{\prime}{ }_{\theta}\left(X_{2}\right)-\omega^{\prime}{ }_{\theta}\left(X_{3}\right)}\right] l_{2}\right\} \frac{\delta l_{2}}{l_{2}} \text {. }
\end{aligned}
$$

The derivatives in these formulas can be computed by the following equations:

$$
\begin{aligned}
& \frac{d \omega_{\theta}^{\prime}(X)}{d r_{2}}=\frac{2 \pi N_{1} N_{2}}{l_{1} l_{2}} k X \sqrt{\frac{r_{2}}{r_{1}}}\left[K+\frac{\left(r_{1}-r_{2}\right)}{\left(r_{1}+r_{2}\right)} \Pi\right] \\
& \frac{d \omega^{\prime}{ }_{\theta}(X)}{d r_{1}}=\frac{2 \pi N_{1} N_{2}}{l_{1} l_{2}} k X \sqrt{\frac{r_{1}}{r_{2}}}\left[K+\frac{\left(r_{2}-r_{1}\right)}{r_{1}+r_{2}} \Pi\right] \\
& \frac{d \omega_{\theta}^{\prime}{ }_{\theta}(X)}{d l_{1}}=M\left[\frac{N_{1} N_{2}}{l_{1} l_{2}}\right] \frac{d X}{d l_{1}}-\frac{\omega^{\prime}{ }_{\theta}(X)}{l_{1}} \\
& \frac{d \omega^{\prime}{ }_{\theta}(X)}{d l_{2}}=M\left[\frac{N_{1} N_{2}}{l_{1} l_{2}}\right] \frac{d X}{d l_{2}}-\frac{\omega^{\prime}{ }_{\theta}(X)}{l_{2}},
\end{aligned}
$$

where $M$ is the mutual inductance between coaxial circles of radii $r_{1}$ and $r_{2}$, the distance between their planes being $X$. Values of $M$ are tabulated against $k^{2}$ in the tables of Nagaoka and Sakurai [14].

A summary of the computations applying these formulas to $\mathrm{H1}$ and $P 1$ is given in table 7. In these computations, the preliminary values of the measured dimensions were used. The variation formula was used to obtain the value of the force for unit current when accurate values of the dimensions were available. 
TABLE 7.-Summary of computations on force due to unit currents for the helices $P 1$ and $H 1$

[The following values of the independent variables were used in the computation:

$$
\begin{array}{lll}
r_{1}=23.09494 \mathrm{~cm} . & l_{1}=27.51662 \mathrm{~cm} . & N_{1}=344 \text { turns. } \\
r_{2}=12.23084 \mathrm{~cm} . & l_{2}=2.66506 \mathrm{~cm} . & N_{2}=41 \text { turns. }
\end{array}
$$

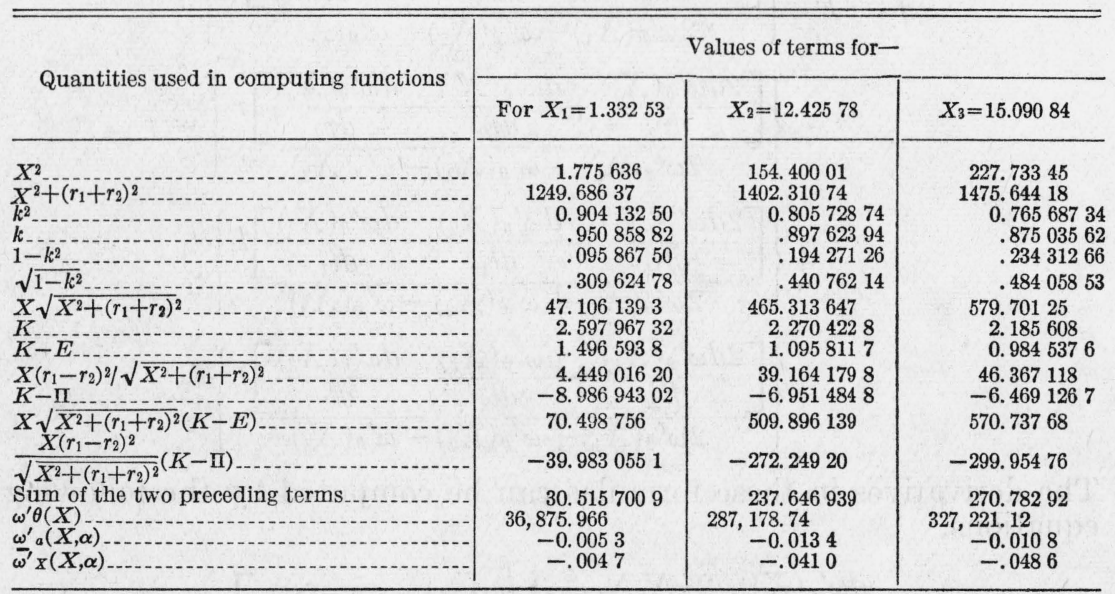

Principal term $\left[2 \omega_{0}^{\prime}\left(X_{1}\right)+\omega^{\prime}{ }_{0}\left(X_{2}\right)-\omega^{\prime}{ }_{\theta}\left(X_{3}\right)\right]=33,709.55$ dynes.

Azimuthal correction term $\left[2 \omega^{\prime}{ }_{a}\left(X_{1}, \alpha\right)+\omega^{\prime}{ }_{a}\left(X_{2}, \alpha\right)-\omega^{\prime}{ }_{a}\left(X_{3}, \alpha\right)\right]=-0.013$.

Axial correction term $\left[2 \bar{\omega}^{\prime} X\left(X_{1}, \alpha\right)+\bar{\omega}^{\prime} X\left(X_{2}, \alpha\right)-\bar{\omega}^{\prime} X\left(X_{3}, \alpha\right)\right]=-0.002$.

$f=33709.54$ dynes.
$F_{H H}=1348.3816$ dynes.

The computations of the coefficients in the variation formula for these two helices gave the equation $\frac{\delta F_{H H}}{F_{H H}}=2.73 \frac{\delta r_{2}}{r_{2}}-2.81 \frac{\delta r_{1}}{r_{1}}+0.091 \frac{\delta l_{1}}{l_{l}}-0.015 \frac{\delta l_{2}}{l_{2}}$.

The following adjustments for differences between the measured values of the dimensions and those used in the above computation were made:

$$
\begin{aligned}
\delta r_{1} / r_{1} & =+21.6 \mathrm{ppm} \\
\delta r_{2} / r_{2} & =+31.1 \\
\delta l_{1} \text { and } \delta l_{2} & =0 .
\end{aligned}
$$

Hence for $H 1$ and $P 1$ at the dimensions of the coils corresponding to their mean temperatures during the observation of the force,

$F_{H H}=1348.414$ dynes.

\section{THE FORCE BETWEEN A HELIX AND A SPIRAL}

In an unpublished paper, Snow has developed a formula for the force produced by unit current in a helix and a spiral. The methods employed were similar to those used on other coil combinations $[10,15]$. The coils were coaxial, as shown in figure 4 .

The nomenclature used in the formula is:

$a_{1}=$ mean radius of fixed helix (same as $r_{1}$ in previous section).

$a_{2}=$ mean radius of moving spiral.

$2 b_{1}=$ axial length of fixed helix (same as $l_{1}$ in previous section).

$2 b_{2}=$ axial length of moving spiral.

$2 c_{2}=$ radial depth of moving spiral.

$N_{1}=$ number of turns on fixed helix.

$N_{2}=$ number of turns on the moving spiral.

The force, $f$, for unit current in the moving coil, $A 1$, and in either half of the single-layer solenoid, $H 1$, is computed as the difference of the same function of two different lengths by the equation

$$
f=\omega^{\prime}\left(z_{2}\right)-\omega^{\prime}\left(z_{1}\right),
$$




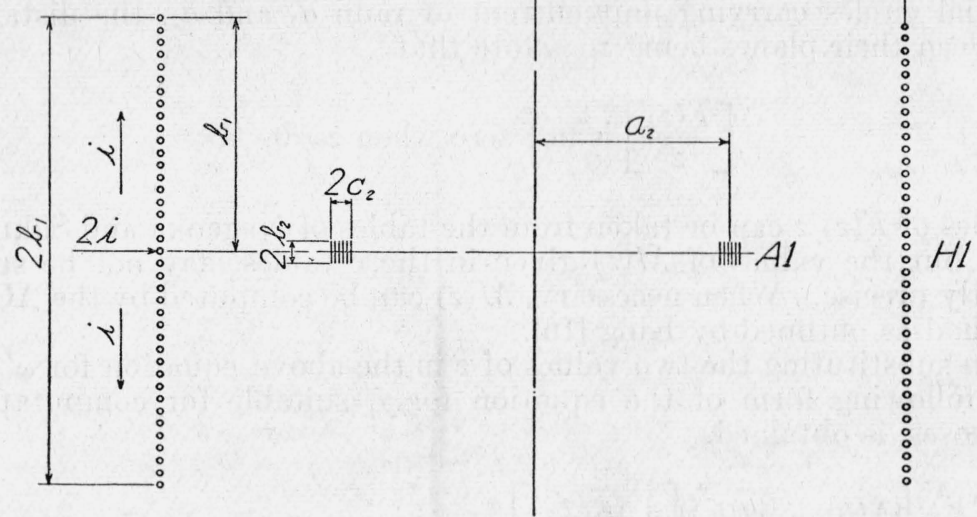

FIgURE 4.-Section showing relative positions of helix H1 and spiral A1.

where $z_{1}=b_{1}$ and $z_{2}=0$,

$$
\begin{aligned}
& \omega^{\prime}(z)=\frac{N_{1} N_{2}}{b_{1}}\left\{\left[1+\frac{c_{2}^{2}}{12 a_{2}^{2}}\right] M(z)\right. \\
& +\frac{1}{12 a_{2}^{2}}\left[\frac{F(z)}{z}\right]\left[A^{2} c_{2}^{2}\left(x^{2}+\beta\right)-2 a_{2}^{2}\left(b_{2}^{2}-c_{2}^{2}\right) \lambda_{1}(x)\right] \\
& +\frac{1}{360 a_{2}^{2}}\left[\frac{F(z)}{z}\right]\left[c_{2}^{2}\left(5 b_{2}^{2}-3 c_{2}^{2}\right)\left\{\beta\left(\frac{2-2 \lambda_{1}(x)-\lambda_{2}(x)}{x^{2}}\right)+2 \lambda_{1}(x)-\lambda_{2}(x)\right\}\right. \\
& \left.\left.-5 b_{2}^{2} c_{2}^{2} \lambda_{1}(x)-\frac{a_{2}^{2}\left(3 b_{2}^{4}-10 b_{2}^{2} c_{2}^{2}+3 c_{2}^{4}\right)}{A^{2}} \cdot \frac{\lambda_{3}(x)}{x^{2}}\right]\right\}
\end{aligned}
$$

The above formula was simplified by using the following:

$$
\begin{aligned}
k^{2} & =4 a_{1} a_{2} /\left[z_{2}+\left(a_{1}+a_{2}\right)^{2}\right] \\
A^{2} & =a_{1}^{2}+a_{2}^{2} \\
x & =z / A \\
\beta & =\left(a_{1}^{2}-a_{2}^{2}\right) /\left(a_{1}^{2}+a_{2}^{2}\right) \\
\lambda_{1}(x) & =-\frac{3 x^{4}+2 x^{2}-\beta^{2}+\frac{3 x^{3} M(z)}{A F(z)}}{x^{4}+2 x^{2}+\beta^{2}} \\
\lambda_{2}(x) & =\frac{3 \beta^{2}-2 x^{2}+\left(5 x^{4}+2 x^{2}-3 \beta^{2}\right) \lambda_{1}(x)}{x^{4}+2 x^{2}+\beta^{2}} \\
\lambda_{3}(x) & =\frac{4 x^{2}-\left(25 x^{4}+4 x^{2}\right) \lambda_{1}(x)+\left(11 x^{4}+10 x^{2}-\beta^{2}\right) \lambda_{2}(x)}{x^{4}+2 x^{2}+\beta^{2}} \\
M(z) & =4 \pi \sqrt{a_{1} a_{2}}\left[\frac{2(K-E)}{k}-k K\right] \\
\frac{F(z)}{z} & =\frac{\pi k}{\sqrt{a_{1} a_{2}}}\left[\frac{\left(2-k^{2}\right)}{\left(1-k^{2}\right)} E-2 K\right] .
\end{aligned}
$$


$M(z)$ is the mutual inductance of two circles whose radii are $a_{1}$ and $a_{2}$, the distance between their planes being $z . F(z)$ is the force between coaxial circles carrying unit current of radii $a_{1}$ and $a_{2}$, the distance between their planes being $z$. Note that

$$
\left[\frac{F(z)}{z}\right] \text { is not zero when } z=0 \text {. }
$$

Values of $F(z) / z$ can be taken from the tables of Nagaoka and Sakurai [14], but the values of $M(z)$. given in those tables may not be sufficiently precise. When necessary, $M(z)$ can be computed by the AGM method as outlined by King [16].

On substituting the two values of $z$ in the above equation for $\omega^{\prime}(z)$, the following form of the equation for $f$, suitable for computation purposes, is obtained.

$$
\begin{aligned}
& f=\frac{N_{1} N_{2}}{b_{1}}\left\{\left[M(0)-M\left(b_{1}\right)\right]\left[1+\frac{c_{2}{ }^{2}}{12 a_{2}{ }^{2}}\right]\right. \\
&+ \frac{1}{12 a_{2}{ }^{2}}\left[A^{2} c_{2}{ }^{2} \beta-2 a_{2}{ }^{2}\left(b_{2}{ }^{2}-c_{2}{ }^{2}\right)\right]\left[\frac{F(z)}{z}\right]_{z=0} \\
&-\frac{1}{12 a_{2}{ }^{2}} \frac{F\left(b_{1}\right)}{b_{1}}\left[A^{2} c_{2}{ }^{2}\left(x_{1}{ }^{2}+\beta\right)-2{a_{2}}^{2}\left(b_{2}{ }^{2}-c_{2}{ }^{2}\right) \lambda_{1}\left(x_{1}\right)\right] \\
&+ \frac{1}{360 a_{2}{ }^{2}}\left[c_{2}{ }^{2} \frac{\left(5 b_{2}{ }^{2}-3 c_{2}{ }^{2}\right)}{\beta}\left\{(2 \beta-4)\left[\frac{F(z)}{z}\right]_{z=0}-\frac{3 M(0)}{A^{2}}\right\}\right. \\
&-5 b_{2}{ }^{2} c_{2}{ }^{2}\left[\frac{F(z)}{z}\right]_{z=0} \\
&+\left.\left\{3 a_{2}{ }^{2} \frac{\left(3 b_{2}{ }^{4}-10 b_{2}{ }^{2} c_{2}{ }^{2}+3 c_{2}{ }^{4}\right)}{A^{2} \beta^{2}}\right\}\left\{4\left[\frac{F(z)}{z}\right]_{z=0}+3 \frac{M(0)}{A^{2}}\right\}\right] \\
&-\frac{1}{360 a_{2}{ }^{2}} \frac{F\left(b_{1}\right)}{b_{1}}\left[c _ { 2 } { } ^ { 2 } ( 5 b _ { 2 } { } ^ { 2 } - 3 c _ { 2 } { } ^ { 2 } ) \left\{\beta\left[\frac{2-2 \lambda_{1}\left(x_{1}\right)-\lambda_{2}\left(x_{1}\right)}{x_{1}{ }^{2}}\right]\right.\right. \\
&\left.\left.\left.+2 \lambda_{1}\left(x_{1}\right)-\lambda_{2}\left(x_{1}\right)\right\}-5 b_{2}{ }^{2} c_{2}{ }^{2} \lambda_{1}\left(x_{1}\right)-\frac{a_{2}{ }^{2}\left(3 b_{2}{ }^{4}-10 b_{2}{ }^{2} c_{2}{ }^{2}+3 c_{2}{ }^{4}\right)}{A^{2} x_{1}{ }^{2}} \lambda_{3}\left(x_{1}\right)\right]\right\}
\end{aligned}
$$

The formula gives the value of $f$ for the moving spiral and one half of the fixed solenoid, if all the dimensions are measured in the same units and if the medium surrounding the coils has unit permeability. Since there are two fixed coils and since the current is reversed in the fixed coils, the computed force, $F_{H S}$, is four times $f$. If $F_{H S}$ is expressed in dynes for an absolute ampere in each coil,

$$
F_{H S}=\frac{4 f}{100} .
$$


The variation in $F_{H S}$ with small variations in $a_{1}, a_{2}, b_{1}, b_{2}$, and $c_{2}$ is

$$
\begin{aligned}
& \frac{\delta F_{H S}}{F_{H S}}=\left[1-\frac{b_{1} F\left(b_{1}\right)}{M(0)-M\left(b_{1}\right)}\right]\left[\frac{\delta a_{1}}{2 a_{1}}+\frac{\delta a_{2}}{2 a_{2}}-\frac{\delta b_{1}}{b_{1}}\right] \\
& -\frac{\left(a_{1}^{2}-a_{2}^{2}\right)}{2}\left[\frac{\left[\frac{F(z)}{z}\right]_{z=0}-\frac{F\left(b_{1}\right)}{b_{1}}}{M(0)-M\left(b_{1}\right)}\right]\left[\frac{\delta a_{1}}{a_{1}}-\frac{\delta a_{2}}{a_{2}}\right] \\
& +\frac{c_{2}^{2}}{3}\left\{\frac{1}{2 a_{2}^{2}}+\frac{A^{2}}{2 a_{2}^{2}}\left[\frac{\beta\left[\frac{F(z)}{z}\right]_{z=0}-\left(x_{1}^{2}+\beta\right) \frac{F\left(b_{1}\right)}{b_{1}}}{M(0)-M\left(b_{1}\right)}\right]\right. \\
& \left.+\frac{\left[\frac{F(z)}{z}\right]_{z=0}-\lambda_{1}\left(x_{1}\right) \frac{F\left(b_{1}\right)}{b_{1}}}{M(0)-M\left(b_{1}\right)}\right] \frac{\delta c_{2}}{c_{2}} \\
& -\frac{b_{2}^{2}}{3}\left[\frac{\left.\frac{F(z)}{z}\right]_{z=0}-\lambda_{1}\left(x_{1}\right) \frac{F\left(b_{1}\right)}{b_{1}}}{M(0)-M\left(b_{1}\right)}\right] \frac{\delta b_{2}}{b_{2}} .
\end{aligned}
$$

A summary of the computations for this coil combination is given in table 8.

TABLE 8.-Summary of computations on force produced by unit currents in the helix, H1, and the spiral moving coil, A1,

[The following constants of the coils were used in the computations:

$$
\begin{aligned}
& \begin{array}{ll}
a_{1}=23.09553 \mathrm{~cm} . & b_{1}=13.75825 \mathrm{~cm} . \\
a_{2}=12.57690 \mathrm{~cm} . & b_{2}=0.3182 \mathrm{~cm} .
\end{array} \\
& \begin{array}{ll}
N_{1}=344 \text { turns. } & \left.c_{2}=0.3260 \mathrm{~cm} .\right]
\end{array} \\
& \mathrm{N}_{2}=45 \text { turns. }
\end{aligned}
$$

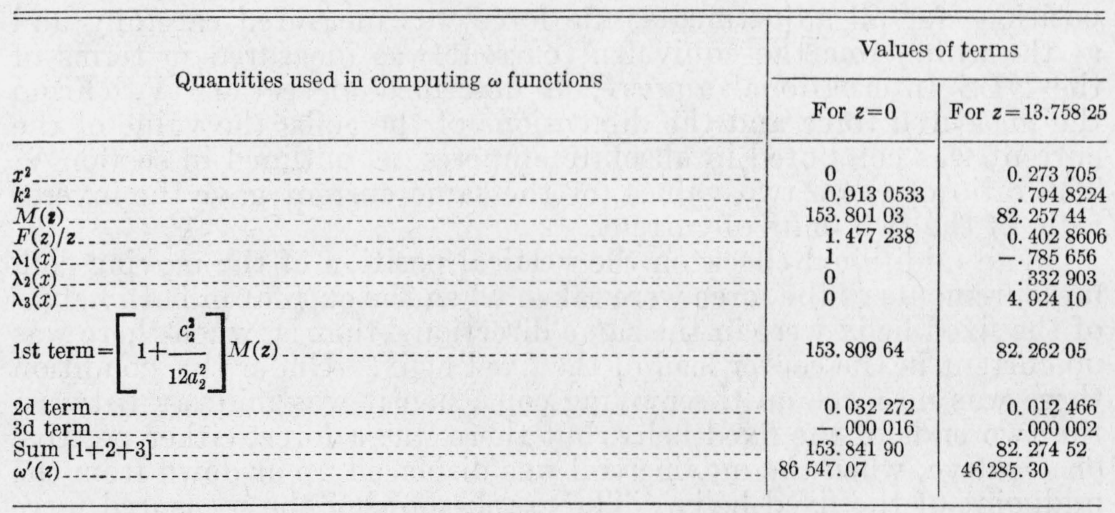

$f=40261.77$ dynes.

The computations of the coefficients in the variation formula for helix $H 1$ and spiral $A 1$ gave the equation $\frac{\delta F_{H S}}{F_{H S}}=2.78 \frac{\delta a_{2}}{a_{2}}-2.85 \frac{\delta a_{1}}{a_{1}}+0.066 \frac{\delta b_{1}}{b_{1}}-0.00085 \frac{\delta b_{2}}{b_{2}}+0.00151 \frac{\delta c_{2}}{c_{2}}$.

The following adjustments for differences between the measured values of the dimensions and those used in the above computation were made:

$$
\frac{\delta a_{2}}{a_{2}}=27.8 \mathrm{ppm} \ldots \ldots \ldots F_{H S}=0.1244 \text { dyne. }
$$
In the computation the measured values were used for all the other dimensions. Hence for $H 1$ and $A 1$,
\[ F_{H S}=1610.595 \text { dynes } \]

for the dimensions of the coils corresponding to their mean temperatures during the observations of the force. 


\section{COMPUTATION OF THE ABSOLUTE VALUE OF THE CURRENT}

The absolute value of the equivalent current, $I_{\mathrm{eq}}$ is computed by the formula $I^{2}{ }_{\text {eq }}=m g / F$. In this formula $m$ is the mass required to restore the equilibrium of the balance when the current is reversed in the fixed coil, $g$ is the value of gravity, and $F$ is the computed force in dynes for an absolute ampere in each coil. The value of the acceleration of gravity at the elevation of the balance has been taken as $980.095 \mathrm{~cm} / \mathrm{sec}^{2}$, as has been used in the earlier reports.

\section{EXPERIMENTAL DETERMINATION OF THE MAXI- MUM FORCE BETWEEN THE COILS}

The determination of the maximum force between the coils was made in practically the same manner as described in the previous reports. The fixed and moving coils were mounted with their axes vertical and with the center of the moving coil in the same horizontal plane as the center of the fixed coil. This same plane also contained the lead to the midpoint of the fixed coil. The planes of the ends of the coil forms were made horizontal by means of sensitive levels and leveling screws. In order to ascertain the correct position of the moving coil with respect to the fixed coil, a series of force measurements was made with a constant current in the coils. The series consisted of measurements with the moving coil at different positions along each of three perpendicular axes, one of which was vertical. The measured force, when plotted as a function of the position of the moving coil along each of the axes, had a maximum value at the correct position on the vertical axis and a minimum value at the correct position on each of the horizontal axes. The moving coil was concentric with the fixed helix when it was at the position of maximum force for vertical adjustments and at the position of minimum force for horizontal adjustments. When the coils were set to the correct positions for all adjustments, the force was measured carefully and at the same time the equivalent current was measured in terms of the NBS International ampere, as described in section IV. From the measured force and the dimensions of the coils, the value of the current was computed in absolute amperes, as outlined in section V. The ratio of these two values for the same current gave the inverse ratio of the two units of current.

As an additional check on the vertical position of the moving coil, measurements of the force were taken when the current in both halves of the fixed helix were in the same direction - that is, when there was no current in the center lead of the fixed helix. Under this condition there was no force on the moving coil when it was midway between the two ends of the fixed helix, but there was a force, either positive or negative, when the moving coil was displaced up or down from the midpoint of the fixed helix. The graph showing the measured force plotted against the vertical displacement of the moving coil was a straight line. From this line, the position of the moving coil at which the force on it was zero was determined. Experimentally, this position was found to be the same as the position for maximum force when the currents in the two halves of the helix were in opposite directions. This was expected, since both methods indicate the position at which coils are concentric. However, the method using the currents in the same direction located the concentric position more accurately than could be done when using the currents in opposite directions. 
The effect of the leads was measured by short-circuiting the twisted lead-in wires as near to the coil windings as possible and measuring the force with normal current in the other coil and in the leads of the coil in question. This force was added to or subtracted from the total force measured to get the true force. A small residual effect might still remain, caused by the fact that a long helix has to have a long axial return for the leads. This was made negligibly small by keeping these return leads in a vertical plane, and by keeping the area of the loop formed by the leads small. The lead residual effect was a function of the projected area of this loop area on a horizontal plane, so that it was not difficult to keep the effect of the loop below $1 \mathrm{ppm}$.

The force was measured as in the previous work by observing the change in the rest point of the balance when the current in the fixed coils was reversed and the weight added (or removed). One person observed and recorded the swings of the balance and another regulated the currents. A series of turning points (usually five) was used to determine the rest point of the balance. Then the current in the fixed coils was reversed, the weight changed, and the rest point was again determined. A series of at least five of these rest points was obtained in determining the mass required to compensate the electromagnetic force under any given set of conditions. The difference in the rest points for the "on" and "off" positions of the weight multiplied by the sensitivity of the balance gave the amount to be added to (or subtracted from) the mass of the weight to give the mass required to balance the electromagnetic force on the moving coil.

The accuracy of the measurement of the force was limited by the irregular oscillations of the balance. The principal cause of these irregularities was the heating produced by the electric currents in the fixed and moving coils. Water cooling was not feasible even for the fixed coils, so that all the heat had to be dissipated into the air. With normal currents the coils generated heat at the rate of about 25 watts for the fixed coil and 2 or 3 watts for the moving coils. If allowed to come to equilibrium, the air in the closed coil case was heated about $3^{\circ} \mathrm{C}$ above the room temperature when the coils were $9^{\circ}$ or $10^{\circ} \mathrm{C}$ above room temperature. Under such conditions the swings of the balance were somewhat erratic. However, when the coil case was ventilated by small openings at the top and bottom, or by drawing air from the top of the coil case with a fan, the temperature of the air in the coil case was the same as that of the room and and the coil temperatures were $6^{\circ}$ or $7^{\circ} \mathrm{C}$ above room temperature. The swings of the balance became more regular after the ventilating system was installed. All of the final results were taken with either the natural or artificial ventilation of the coil case.

The interior of the fixed coil formed a chimney through which flowed the air that both cooled and disturbed the moving coil. In an attempt to streamline the air flow through the chimney and around the moving coil, a honeycomb made of small tubes was placed in the chimney directly under the moving coil. Some improvement in the operation of the balance was noted after the installation of the honeycomb so that it was used when the final observations were made.

After the coils were adjusted to be coaxial and concentric, about 10 determinations of the force were made with the same currents and with the coils at nearly constant temperatures. The conditions were 


\section{Journal of Research of the National Bureau of Standards}

sufficiently constant so that average values of temperature and force could be taken for the whole set and the computation made for this average condition. The mechanical measurements of the dimensions of the coils were made after the force measurements. In order to reduce the uncertainty caused by temperature corrections, one set of the mechanical measurements was carried out while each coil was held at a temperature approximately the same? as"the average temperature it attained in the current balance.

Tables 9 and 10 contain a summary of all the sets of observations which were taken after the coils were adjusted to their correct positions, and after the erratic oscillations of the balance had been minimized. From these the final average result for each set of coils is obtained. This computation is outlined in table 11.

TABLE 9.-Results of measurements of force with helices $H 1$ and P1

[Note: $\varepsilon=$ average difference in scale reading of rest points of the balance corresponding to "on" and "off", positions of weight. Sensitivity of balance: $1.21 \mathrm{mg}$ per $\mathrm{cm}$. Mass of weight (a platinum cylinder): 1.427655 grams]

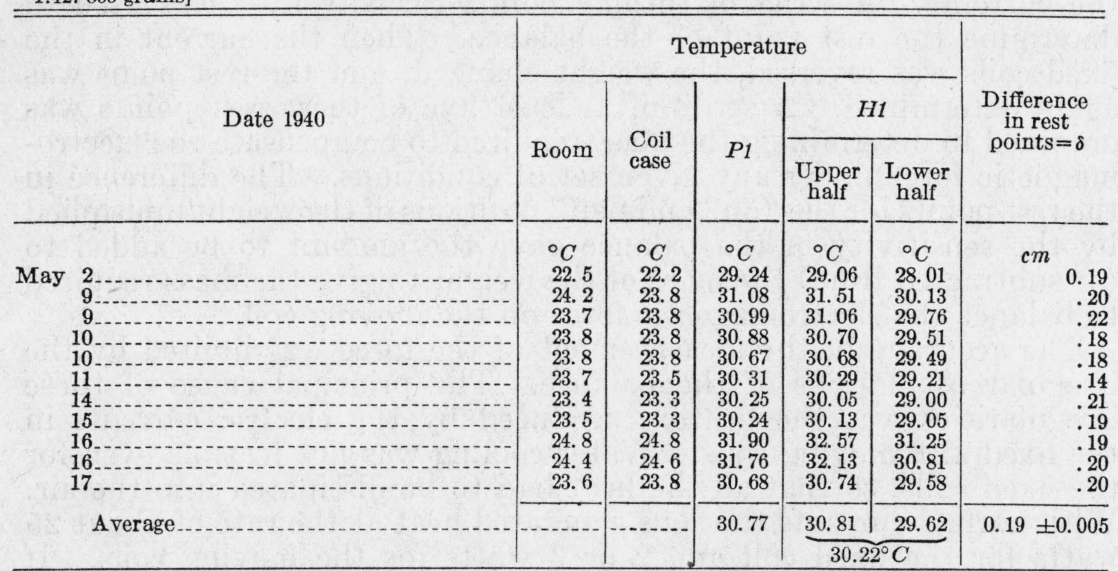

Average $\delta \times$ sensitivity of balance $=0.231 \pm 0.006 \mathrm{mg}$.

TABLE 10.-Results of measurements of force with coils H1 and A1

[Note: $\delta$ is the average difference in scale reading of the rest points of the balance corresponding to "on" and "off" positions of weight. Sensitivity of balance: $1.17 \mathrm{mg}$ per $\mathrm{cm}$. Mass of weight (a platinum cylinder): 1.705316 grams]

\begin{tabular}{|c|c|c|c|c|c|c|c|}
\hline \multirow{3}{*}{ Date 1940} & \multicolumn{5}{|c|}{ Temperature } & \multicolumn{2}{|c|}{$\begin{array}{l}\text { Difference in rest } \\
\text { points }=\delta\end{array}$} \\
\hline & \multirow{2}{*}{ Room } & \multirow{2}{*}{$\begin{array}{l}\text { Coil } \\
\text { case }\end{array}$} & \multirow{2}{*}{$A 1$} & \multicolumn{2}{|c|}{$H 1$} & \multirow{2}{*}{$\begin{array}{c}\text { Ob- } \\
\text { served }\end{array}$} & \multirow{2}{*}{$\begin{array}{l}\text { Corrected for } \\
\text { departure of } \\
A 1 \text { from } \\
29.94^{\circ} \mathrm{C}\end{array}$} \\
\hline & & & & $\begin{array}{l}\text { Upper } \\
\text { half }\end{array}$ & $\begin{array}{c}\text { Lower } \\
\text { half }\end{array}$ & & \\
\hline \multirow[t]{3}{*}{ June 15} & $\begin{array}{l}{ }^{\circ} C \\
25.1 \\
25.3 \\
25.4 \\
25.4 \\
25.3 \\
24.2 \\
24.2 \\
24.4 \\
24.5 \\
24.5\end{array}$ & $\begin{array}{l}{ }^{\circ} C \\
25.2 \\
25.4 \\
25.5 \\
25.5 \\
25.5 \\
24.5 \\
24.6 \\
24.7 \\
24.7 \\
24.7\end{array}$ & $\begin{array}{l}{ }^{\circ} C \\
30.08 \\
30.26 \\
30.37 \\
30.42 \\
30.42 \\
29.41 \\
29.50 \\
29.68 \\
29.66 \\
29.70\end{array}$ & $\begin{array}{c}{ }^{\circ} C \\
31.90 \\
32.04 \\
32.19 \\
32.22 \\
32.24 \\
31.16 \\
31.27 \\
31.43 \\
31.47 \\
31.48\end{array}$ & $\begin{array}{c}{ }^{\circ} C \\
31.00 \\
31.14 \\
31.31 \\
31.34 \\
31.35 \\
30.32 \\
30.42 \\
30.56 \\
30.60 \\
30.62\end{array}$ & $\begin{array}{c}c m \\
0.09 \\
.11 \\
.06 \\
.11 \\
.09 \\
-.01 \\
.03 \\
.02 \\
.03 \\
.07\end{array}$ & $\begin{array}{l}\quad c m \\
0.07_{9} \\
.08_{4} \\
.02_{4} \\
.07_{0} \\
.05_{0} \\
.03_{6} \\
.06_{8} \\
.04_{3} \\
.05_{5} \\
.09_{1}\end{array}$ \\
\hline & & ......... & 29.94 & 31.74 & 30.87 & \multirow[t]{2}{*}{$0.06_{0}$} & \multirow[t]{2}{*}{$0.060 \pm 0.005$} \\
\hline & & & & \multicolumn{2}{|c|}{31.30} & & \\
\hline
\end{tabular}


TABLE 11.-Calculation of final results

[Value of acceleration of gravity $980.095 \mathrm{~cm} / \mathrm{sec}^{2}$ ]

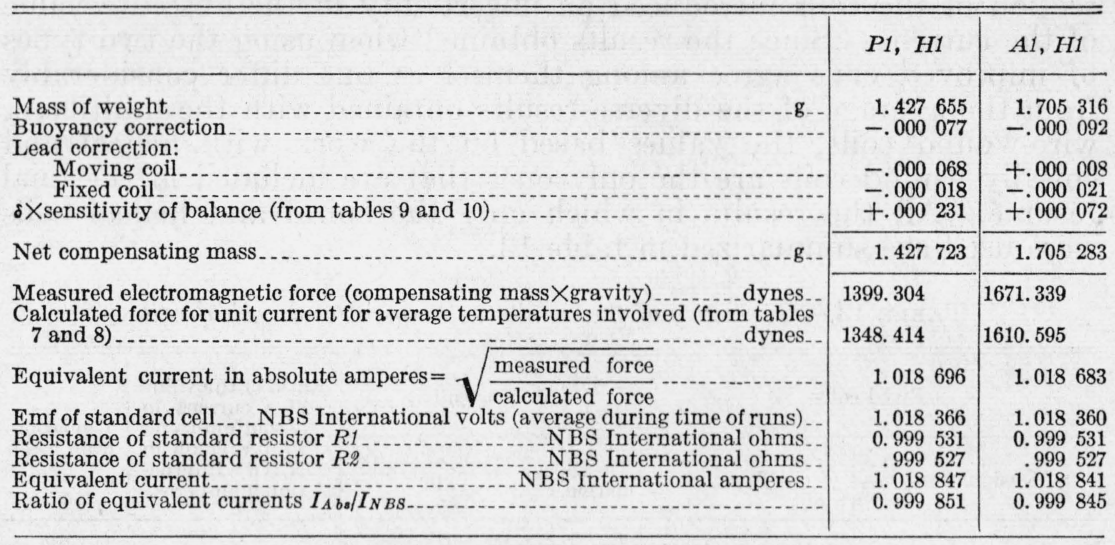

\section{DISCUSSION OF RESULTS}

The ratio of the value of a current in absolute amperes to its value in NBS International amperes, as obtained from measurements with the helix $H 1$ as the fixed coils of the current balance, is the average of the two ratios given at the end of table 11. This average ratio is

1 NBS International ampere $=0.999848$ absolute ampere.

In the previous investigations the sources of error have been discussed in detail $[2,8]$. In general the same discussion applies to this determination. However, several of the larger sources of error have been reduced in size. Table 12 gives the errors that are estimated to be as large as 1 part in a million. The uncertainty appears to be about 10 parts in a million for the results involving $A 1$ and somewhat less for the results with $P 1$. This does not include the uncertainty in the value of gravity, which may be as large as $10 \mathrm{ppm}$.

TABLE 12.- Sources of error causing an uncertainty in ratio $I_{\mathrm{NBS}} / I_{\mathrm{ABS}}$ as large as $1 \mathrm{ppm}$

\begin{tabular}{|c|c|c|c|c|c|}
\hline & \multicolumn{2}{|c|}{ Fixed coil $H 1$} & $2=$ & \multicolumn{2}{|c|}{ Fixed coil $H 1$} \\
\hline & $\begin{array}{c}\text { Moving } \\
\text { coil } \\
P 1\end{array}$ & $\begin{array}{c}\text { Moving } \\
\text { coil } \\
A 1\end{array}$ & & $\begin{array}{c}\text { Moving } \\
\text { coil } \\
P 1\end{array}$ & $\begin{array}{c}\text { Moving } \\
\text { coil } \\
A 1\end{array}$ \\
\hline Adjustment of coils... & $p p m_{1}$ & $p p m_{1}$ & Finite cross section of moving coil. & $p p m$ & $p_{3}$ \\
\hline Temperature of coils & & 1 & Distribution of current over cioss & & \\
\hline $\begin{array}{l}\text { Measurement of the force....... } \\
\text { Lead corrections }\end{array}$ & & 2 & section of wire & 1 & 1 \\
\hline $\begin{array}{l}\text { Lead corrections } \\
\text { Radius of the fixed coil }\end{array}$ & & 2 & Calibration of standard of mass... & 2 & $\begin{array}{r}2 \\
10\end{array}$ \\
\hline $\begin{array}{l}\text { Radius of the fixed coll } \\
\text { Radius of the moving coil........... }\end{array}$ & & & Acceleration of gravity & & \\
\hline
\end{tabular}

The result of this determination differs by 14 parts in a million from the weighted mean as published in 1939 [2]. That weighted mean included some results taken with the older type multilayer wire- 
wound coils. Since the position of the wires in those coils was uncertain, the uncertainty in the distribution of current over the cross section of the coils introduced an uncertainty in the absolute value of the current. Since the results obtained when using the two types of improved coils agree among themselves but differ considerably from the average of the diverse results obtained with the multilayer wire-wound coils, the values based on the work with helical and spirally wound coils are the only ones that are included in the final résumé. All the results in which only the spiral and helical coils were used are summarized in table 13.

TABLE 13.-Summary of the results with spiral and helical coils

\begin{tabular}{|c|c|c|c|c|c|}
\hline \multicolumn{2}{|c|}{ Fixed coils } & \multicolumn{2}{|r|}{ Moving coil } & \multirow{2}{*}{$\begin{array}{l}\text { Ratio of the value } \\
\text { of a current in } \\
\text { absolute amperes } \\
\text { to its value in } \\
\mathrm{N} \mathrm{B} \text { S Interna- } \\
\text { tional amperes }\end{array}$} & \multirow{2}{*}{$\begin{array}{l}\text { Deviation } \\
\text { from mean }\end{array}$} \\
\hline Designation & Tyре & $\begin{array}{l}\text { Desig- } \\
\text { nation }\end{array}$ & Type & & \\
\hline$B 1, B 2 \ldots$ & $\begin{array}{l}\text { Spiral of alumi- } \\
\text { num ribbon on } \\
\text { aluminum form. }\end{array}$ & $\begin{array}{l}A 1 \\
P 1\end{array}$ & $\begin{array}{l}\text { Aluminum ribbon } \\
\text { Copper wire }\end{array}$ & $\begin{array}{r}0.999853^{\mathrm{a}} \\
.999851^{\mathrm{a}}\end{array}$ & $\begin{array}{r}p p m \\
-3 \\
-1\end{array}$ \\
\hline \multirow{2}{*}{ Average. } & \multirow[t]{2}{*}{$\begin{array}{l}\text { Helix of copper } \\
\text { wire on glass } \\
\text { form. }\end{array}$} & \multirow[t]{2}{*}{$\begin{array}{l}A 1 \\
P 1\end{array}$} & \multirow[t]{2}{*}{$\begin{array}{l}\text { Aluminum ribbon } \\
\text { Copper wire....... }\end{array}$} & $\begin{array}{l}.999845 \\
.999851\end{array}$ & $\begin{array}{l}+5 \\
+1\end{array}$ \\
\hline & & & & 0.999850 & \pm 3 \\
\hline
\end{tabular}

a These values were taken from the preceding paper [2].

The determinations given in table 13 with the two different types of fixed coils are nearly independent. In the determination with the fixed coils, $B 1$ and $B 2$, the ratio of radii of each moving coil to each fixed coil was individually determined by an electrical method. From these data, the ratio of the radii of the moving coils, $A 1$ and $P 1$, was obtained. This ratio was used to obtain the radius of $A 1$ from the measured radius of $P 1$. Hence only the one result obtained when using $H 1$ and $P 1$ was entirely independent of the electrical method of measuring the ratio of the radii.

The authors are of the opinion that the best value of the ratio of the units of current as the result of the work at the National Bureau of Standards is

\section{NBS International ampere $=0.999850$ absolute ampere.}

The authors acknowledge assistance from many members of the staff of the National Bureau of Standards and in particular from H. L. Curtis, C. Snow, and C. Moon.

\section{REFERENCES}

[1] P. Vigoureux, An absolute determination of the ampere, Roy. Soc. Phil. Trans. (London) R36A, 133 (1936).

[2] H. L. Curtis, R. W. Curtis, and C. L. Critchfield, An absolute determination of the ampere, using improved coils, J. Research NBS 22, 485 (1939) RP1200.

[3] H. L. Curtis, C. Moon, and C. M. Sparks, An absolute determination of the ohm, J. Research NBS 16, 1 (1936) RP857.

[4] H. L. Curtis, C. Moon, and C. M. Sparks, A determination of the absolute ohm, using an improved self inductor, J. Research NBS 21, 375 (1938) RP1137. 
5] C. Moon, Apparatus for comparison of length 'of 'gages, BS!J. Research 10, 249 (1933) RP528.

[6] C. G. Peters and C. H. Cragoe, Measurements on the thermal dilatation of glass at high temperatures, Sci. Papers BS 16, 449 (1920) S393.

[7] C. Moon, A precision cathetometer, J. Research NBS 14, 363 (1935) RP774.

[8] H. L. Curtis and R. W. Curtis, An absolute determination of the ampere, BS J. Research 12, 665 (1934) RP685.

[9] H. L. Curtis, Electrical Measurements (McGraw-Hill Book Co., New York, N. Y., 1937).

[10] C. Snow, Mutual inductance and force between two coaxial helical wires, J. Research NBS 22, 239 (1939) RP1178.

[11] L. V. King, On the Direct Numerical Calculation of Elliptic Functions and Integrals (Cambridge University Press 1924).

[12] F. W. Grover, On the use of arithmetico-geometric mean series for the calculation of elliptic integrals, with special reference to the calculation of induction, Phil. Mag. [7] 15, 1115 (1933).

[13] H. Nagaoka and S. Sakurai, The Tables of the Elliptic Integrals $K$ and $E$, Sci. Papers Inst. Phys. Chem. Research (Table No. 1), Tokyo (1922).

[14] H. Nagaoka and S. Sakurai, Tables for Facilitating the Calculation of SelfInductance of Circular Coil and of Mutual Inductance of Coaxial Circular Currents. Sci. Papers Inst. Phys. Chem. Research (Table No. 2), Tokyo (1927).

[15] C. Snow, The attraction between coils in the Rayleigh current balance, BS J. Research 11, 681 (1933) RP615.

[16] L. V. King, On some new formulae for the numerical calculation of the mutual induction of coaxial circles, Proc. Roy. Soc. (London) [A], 100, 60 (1921).

Washington, February 21, 1941. 